\title{
Magnetic Pulse Welding Technology
}

\author{
Ahmad K. Jassim \\ Research and Development Department \\ The State Company for Iron and Steel-Ministry of Industry \\ Basrah, Iraq \\ Email: ahmadkj1966@yahoo.com
}

\begin{abstract}
In this paper, the benefits of using Magnetic Pulse machine which is belong to Non-conventional machine instead of conventional machine. Magnetic Pulse Technology is used for joining dissimilar metals, and for forming and cutting metals. It is a non contact technique. Magnetic field is used to generate impact magnetic pressure for welding and forming the work piece by converted the electrical energy to mechanical energy. It is enable us to design previously not possible by welding dissimilar materials and allowing to welds light and stronger materials together. It can be used to weld metallic with non metallic materials to created mechanical lock on ceramics, polymers, rubbers and composites. It is green process; there is no heat, no radiation, no gas, no smoke and sparks, therefore the emissions are negligible.
\end{abstract}

Keywords: Non-conventional machine, magnetic pulse welding, magnetic pulse forming, magnetic field, magnetic pressure.

\section{Introduction}

The designer and manufacturer of automobiles, aerospace and railway are focused on the environmental condition by control the air pollution. They tried to reduce the consumption of energy and fuel by use the lighter weight metals, fuel cell power and hybrid gas as well as electrical power to drive the cars, planes and trains. Light weight aluminium material is best suitable for application in automobiles as well as in aerospace structure, shipbuilding, and railway. To improve fuel efficiency and control air pollution should be reduce the weight of automobiles and aerospace etc. Therefore, need to welded and used aluminium with stainless steel structure for example. It is difficult to weld aluminium to stainless steel by conventional technique due to thermal and metallurgical incompatibility because a large difference in their melting points and due to formation of brittle inters metallic compounds. To obtain a good quality need a special machine which belongs to the field of non conventional machines to do this kind of welding to obtain a good quality? Non conventional machining is a recent development in machining techniques, based 
on laser welding, electric discharge welding, ultrasonic welding, magnetic pulse welding etc. It has many advantages like, do not require the direct contact of tool and work piece, machines produce high accuracy, produce a good surface finish which do not need any finishing process. It does not require periodic adjustments as is common with conventional machining. The tool life is higher than the tool life of conventional welding machines because less or no mechanical wear occurs in the tool after using like magnetic pulse welding [10, 13, 15 and 21]. Since the end of 1950's strong pulsed magnetic fields were used for very fast forming operations working on materials with high electrical conductivity. In 1959 the magnetic pulse forming (MPF) process principle has been patented by Harvey and Brower. MP machine is one of the new nonconventional machines which are used for welding, forming and cutting. It is difficult to decide how to weld dissimilar metals together, because they have difference melting temperatures. Magnetic pulse welding is a cold process; therefore, it is possible to use it for welding dissimilar metals. MPW is solid state joining process of conductive metals such as aluminium, brass or copper to steel, titanium, stainless aluminium, magnesium copper and most other metals. Late 1960's and early 1970's MPW process was developed for nuclear energy applications. MPW is the process classified under pressure welding according to DIN 1910-100:2008 and DIN 14610:2004 according to types of energy sources under name of movement of a mass which is define as a physical phenomenon on which is provides the energy required for welding either by transmission to or transmission within the work piece. It is classified to five types of movement of mass welding. One of them is shock welding which is define as welding with pressure in which the work pieces are welding by the application of a striking force. The heat generated by the sudden collision contributes to the welding. Shock welding is classified to explosive welding and magnetic pulse welding. MPW is define as a shock welding in which a high current pulse passing through a coil surrounding the work pieces produces a magnetic field which exerts the welding force.

\section{Magnetic Pulse Welding}

MPW is a solid state welding process analogous to explosive welding in which a high speed oblique impact of two work pieces creates a weld. MPW is lap welding method; the two work pieces are placed in parallel position with small gap between them and with or without small angle, to achieve impact pressure and creating the correct parameters for welding. MPW is a pulsing process (single shot welding process); which is done with high velocity up to $350 \mathrm{~m} / \mathrm{s}$ and with pulsing up to 12 pulses per minute. MP processes 
are a repulsive force which is generated by opposite magnetic fields in adjacent conductors. Magnetic pulse welding is based on the concept of discharging a high energy current through a coil surrounding the work piece during a very short period of time. The high and extremely fast current creates magnetic forces between the coil and the work piece that accelerate the work pieces to generating a solid state cold welding [23]. MPW process is similar to explosive welding process and they are classified under welding with movement of mass. Therefore, the main parameters of design explosive welding can be used for design magnetic pulse welding which include speed and impact angle.

\section{Magnetic Pulse Process}

Magnetic pulse forming is a non-contact process. There is a small gap between coil and work piece. This gap is effect on the magnetic pulse force and help to obtain a high impact pressure. Primary circuit drives the process, a significant amount of energy usually between 5 and $200 \mathrm{KJ}$ is stored in a large capacitor, or bank capacitors by charging to a high voltage usually between $3,000 \mathrm{~V}$ and $30,000 \mathrm{~V}$, and the peak current is typically between $10^{4} \mathrm{~A}$ to $10^{6} \mathrm{~A}$, while the time to peak current is tens of microseconds. This creates an extremely strong transient magnetic field in vicinity of the coil $[6,17]$.
The metallic work piece nearby will have currents induced which are in opposite direction of the primary current. The opposed fields in the coil and work piece set up an electromagnetic repulsion between the coil and work piece. The electromagnetic force can produce stress in the work piece larger than the material flow stress several times. Ultimately, this can deform the work piece plastically and accelerate it at high velocities exceeding $100 \mathrm{~m} / \mathrm{s}[5,6,17]$.

Materials with high conductivity are very well suited to forming with magnetic pulse forming because material with low conductivity requires a high ringing frequency for effective forming to induce eddy currents in the work piece. Metals with low electrical conductivity like titanium and austenitic stainless steel are almost impossible to form directly, but they can be formed with add of a more conductive driver plate [6]. Electromagnetic metal forming is a high energy rate metal forming process. In this process, the electrical energy is converted to mechanical energy with the use of a magnetic field. Moreover, the process has a high repetition rate.

The magnetic pulse forming can be used successfully as assembly process to join and form the components with different shapes and sizes. This MPW process executed at a very high speed and takes just milliseconds. Shot life of the coil is the limiting factor for an 
industrially viable system because the deformation in the coil $[17,5]$.

\section{Application of Magnetic Pulse}

MPW process has large variations of application, because it can be considered as a cold welding process which opens a wide range of interesting applications. Also magnetic pulse processes can be used for further application that might not be considered in traditional welding. The magnetic pulse process has successfully been applied in industrial fields such as automotive, aerospace, ordnance, consumer products, packaging and electrical industry.

\section{Advantages of MPW}

The most interesting scope of the MPW is the possibility of welding numerous materials that earlier have been considered as materials with poor weld ability, or not weld able at all. This was the aim of the magnetic pulse welding process. Magnetic pulse welding has many advantages, which include Cost, Environment, Quality, and Productivity [3, 5, $14,20,23]$.

MPW cuts the costs of manufacturing processes and components, because the welding process is done without use of consumable materials like filler wire and shield gases. The process does not need exhaust gases vent, energy consumption is lower than in conventional methods, there is no value added for pre and post cleaning process $[5,17]$. The process does not require heat. Therefore, it will avoids the problems that occur in conventional welding, when the heat is applied too much or too little like warping, and other problems with the joint therefore that will reduce the cost of repair or rework [17]. On the other hand, the equipment can be operated with unskilled labour. The MPW machine does not require periodic adjustments as is common with conventional machinery [21].

MPW is green process. There is no heat, no radiation, no gas, no smoke and sparks therefore the emissions are negligible [5]. In addition, MPW is very suitable for working environment condition due to a low noise level. The welding can be undertaken without damaging the surrounding.

With the MPW process, a high quality of products can be produce because it is a cold process without heat treatment degradation and no heat affect zone, which eliminates the localized annealing [5]. There is no corrosion development at the welding area and the joint interface. The welding joints are stronger than the weaker base metal; they have higher strength with lower weight. The parts can be immediately handled after welded. There is no internal stress created in the materials during the welding process, and no future stress release processes are required, therefore it will avoid the creation of micro 
cracks in the weld area. Finally, the magnetic pulse welded parts can be inspected by using the same way of inspection explosive welding parts because all of them are cold process and they have similar process except the method of generated pressure.

MPW enables us to design previously not possible by welding dissimilar materials and allowing to welds light and stronger materials together. It can be used for joining metallic and non metallic materials to created mechanical lock on ceramics, polymers, rubbers and composites. The equipment can easily be re-tooled for different applications and easy for automation [5, 15, 21]. MPW suitable for high volume production, single system can easily be welded one million parts a year [8]. Different parts can be welded in short setup time.

\section{LIMITATIONS OF MPW}

MPW has limitations like other kind of welding $[3,11]$. Only conducting materials can be formed directly. But non- conductors a conducting driver plate must be used for forming. The thickness of sheet to weld is limited today up to $6 \mathrm{~mm}$ for aluminium and1$2 \mathrm{~mm}$ for steel, for forming to $11 \mathrm{~mm}$ for aluminium and $3 \mathrm{~mm}$ for steel. It is difficult to find an optimum spacing between the parts to welded, which is important to generate the appropriate impact speed. High power required for less conductive material. It is difficult to weld AL sheet and heat sensitive AL-Li sheet [11]. The practical limitations of MPW relate to handling very high electrical currents. The major limitation of MPW equipment concerns the electrical connections between capacitors, switch, and coil. Very large sheet metal components cannot be formed due to problems in design of very large coils. It is expensive equipment, just if able only by important mass production.

\section{Components of a MPW machine}

There are different sizes and shapes of MPW machines depending on the design of the manufactures, but the electrical layout of the machine systems is fixed and the same for all machines as shown in figure (1). The system consists of four units: pulse generator, control cabinet, workstation, and operational unit [3, $5,15,16$, and 18].

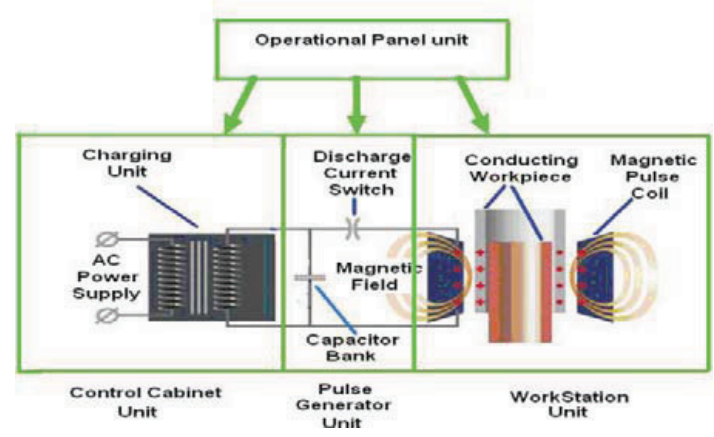

Figure1: The electrical layout of the magnetic pulse welding machine.

Pulse generator unit consist from capacitor bank that stores electrical energy and discharges it across the forming or welding 
coil in a very short time interval and discharge current switch, which usually consists of a set of large diameter copper bus bears. The control cabinet consist from charging unit and AC power supply. The work station Unit consist from magnetic pulse coil, conducting work piece, field shaper (optional) and electrical cables. The operational panel unit content the programmable logic controller (PLC) system which is a digital computer used for automation of the process by control and monitor the quality of the magnetic pulse [15]. The pulses per minute for all MPW machines are reached up to 12 pulses per minute, and the peak current (non shortcut) reached up to $2000 \mathrm{kA}$ depending on the size of the machine. The discharging energy reached up to $180 \mathrm{~kJ}$ or more and the productivity of these machines between 10 to 600 parts per minute according to the specification of machines that produce in Pulsar, ESAB, PST and Elmag [21,22,23, 24]. The magnetic pulse machine should be designed and built to meet the safety requirements of EN 60204 safety of machinery - electrical requirements of machines, ANSI C57.12.58-1999 and IEEE standard C95.1, 1999 Edition for EMF exposure compliance to ensure the safety aspects of the machines and their operation [15].

\section{Parameters influence in MPW}

The main essential components that effect on the MPW and MPF are includes coil, field shaper, capacitor bank, and the work piece materials, as well as the connection cables to connect the components of machine.

The coil is one of the main elements in the magnetic pulse machine that is designed depending on the process and the geometry of the work piece that will be welded or forming etc. Coil can be designed and manufactured with different ways to be used as compression coils, expansion coils and flat forming coils as shown in Figures (2 and 3 ).

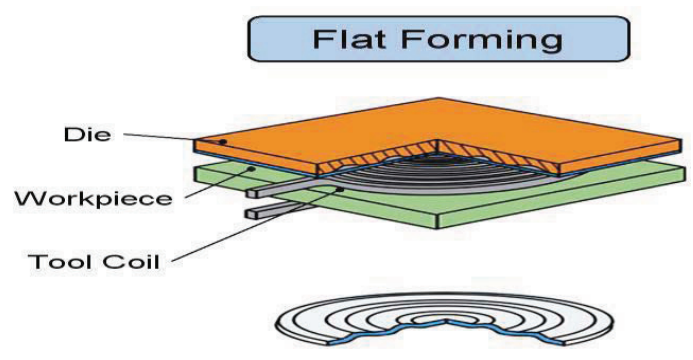

Figure 2: Flat forming Coil

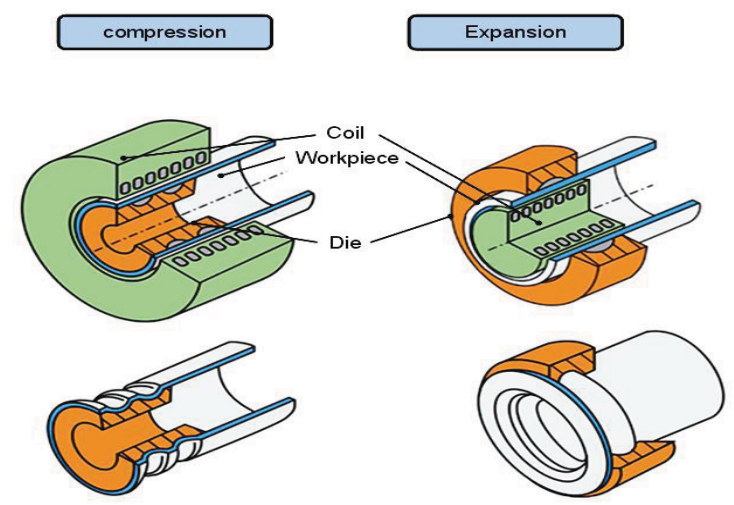

Figure 3: Compression and expansion Coils 
The coils can be classified into three main types of coils according to the number of turns, the shape of coil and the material of the coil. Coil classified to single and multi turn coils [6]. Also it can be classified according to shapes of coil $[2,8,9,10,12]$ to Flat coil. (I shape flat coil with one turn, $\mathrm{H}$-shape flat coil with one turn, E-shape flat coil with one turn), Rectangular cross section coil, Tapered cross section coil, Barrel coil or coil gun, Bifilar coil, Spiral flat coil, Helical coil (solenoid) and Round coil. As well as, it is classified according to material of coil $[2,6,7,9,10,12]$ to copper coil, Chromium - Copper alloy coil, Brass coil, High strength aluminium alloys coil, Copper-beryllium alloys coil and Oxide dispersion strengthened materials.

A field shaper is a practical tool, which is used mainly for magnetic pulse forming and assembly operations of tubular work pieces, which serves to concentrate the magnetic flux and produce the magnetic pressure over the desired area of the work piece. Field shaper is used to increase the service life of coil and concentrate the large magnetic pressure in a desired area with homogenized distribution of magnetic pressure as shown in figure (4). Manufacturing of field shaper is more economical and faster than special coil. The magnetic pressure can be achieved with field shaper is greater than without it [19].
Capacitor bank is the heart of magnetic pulse welding system. It is consist from a number of capacitors that store energy up to $200 \mathrm{KJ}$ [6].

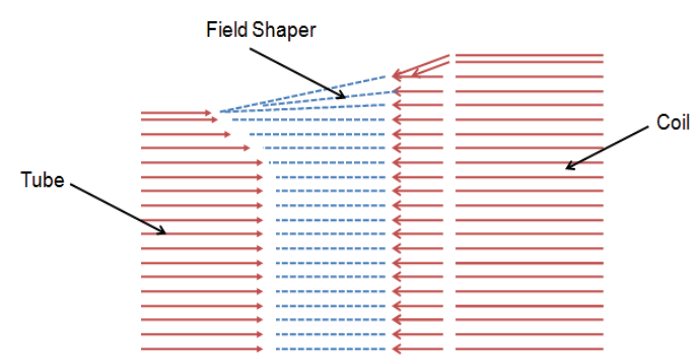

Figure 4: Pressure diagram of magnetic tube compression forming with field shaper.

The basic principle of the magnetic pulse system is that an extremely high current is discharge through a coil, creating an eddy current in the conductive work piece [1]. The important feature of magnetic pulse forming and welding is that the work piece must be conductive enough to create the magnetic forces that must be applied to achieve the right parameters for welding. The efficiency of magnetic pulse forming is directly related to the resistance of the work piece materials. This limitation of thickness depends on the energy consumption of magnetic pulse device, materials specific density and strength of the inductor [4].

The required forming pressure is a function of a combination of the wall thickness, the electrical conductivity, the yield strength, and the geometrical configuration of the work piece [21]. The most efficient forming 
operation is obtained when the skin depth equals to the wall thickness of work piece. The Skin depth $\delta$ is defined as the depth below the surface of the conductor work piece. One of the main limitations in MPW machines is the connection of the components (coil, capacitor bank and switch) because cables with special specification are needed [4].

\section{Inspection of MPW}

There are no international standard specifications defined that can be used for inspection of the magnetic pulse weld process and for quality control. The methods of inspection can be divided into two type's non-destructive and destructive inspection. Non-destructive inspection includes Radiographic inspection and Ultrasonic inspection based on ANSI/ASTM A578. But Destructive inspection includes Shear strength test based on ASTM/ASME A-263, A-264 or A-265 or peel test, Pressure or vacuum leak test (Helium leak test), Pressure burst test, Pressure cycling test, Metallographic analysis test, Temperature cycling test, Tension test and Chisel test.

\section{Analysis of the relationship between the parameters}

MPW is a technique for forming metals by means of plastic deformation generated by a repulsive force on account of the interaction between the magnetic field of coil and the current induced in the work piece that happened with high velocity. Figure (5) shows the main parameters that influence on MPW and figure (6) shows the system of welding sheet metal.

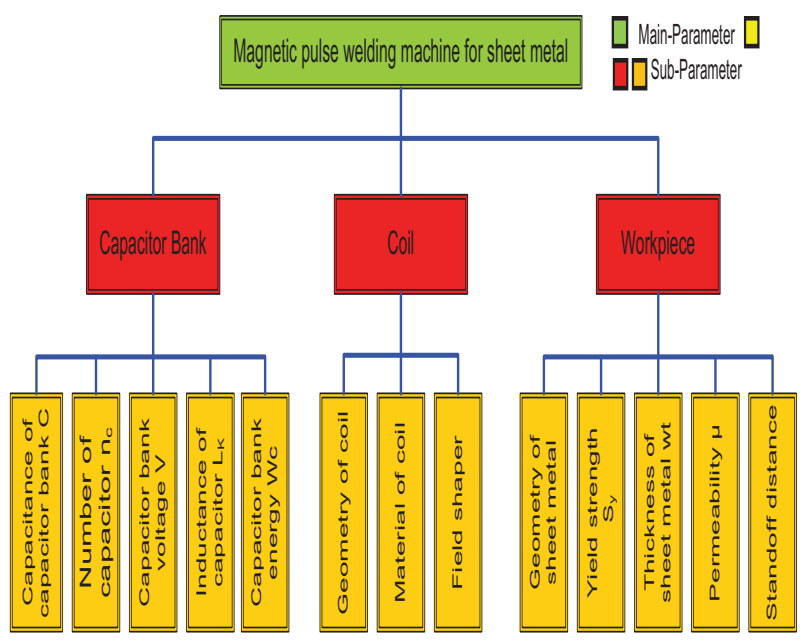

Figure 5: Parameters' influence on the MPW for sheet metal

The magnetic pulse force is very important to obtain the impact weld for sheet metals. Many parameters influence on the magnetic pulse force which includes current, permeability, inductive and standoff distance. Standoff distance is defined as the gap between the sheet metals which has one optimum value that gives the maximum tensile strength of the weld. It has an influence on the magnetic pulse force. 


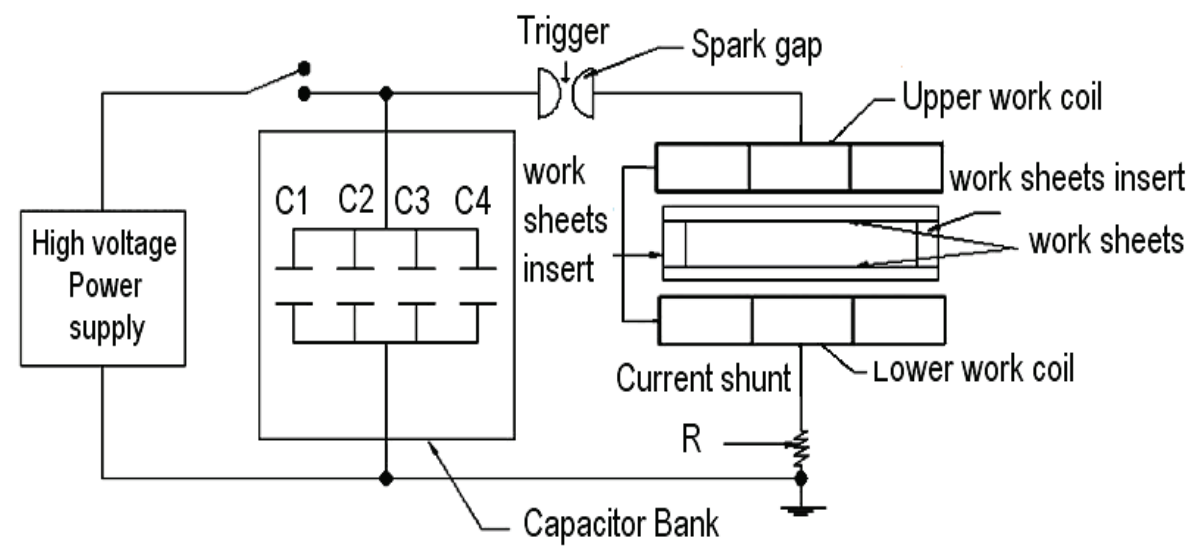

Figure 6: MPW system for welding sheet metals.

Therefore, the quality of weld and the consumption of energy depend on the standoff distance. The duration of applied pressure is very important to obtain high impact pressure. There are different parameters that influence on the magnetic pressure such as skin depth.

\section{Conclusion}

Magnetic pulse technology is one of the new non-conventional methods that used for welding dissimilar metals with high productivity reached to 600 parts per minute. It is enable us to design previously not possible by welding. The process is green process. It is executed at a very high speed and takes just milliseconds. It can be used for variations of application because it is cold process. It is successfully applied in industrial field such as automotive, aerospace, ordering, consumer products, packaging and electrical industry. The advantages of magnetic pulse technology include reducing the cost, good environmental condition, high quality of products, cold process and high productivity. As well as, the possibility to welding, forming and cutting numerous materials. The limitation of this kind of technology only conducting materials can be formed directly.

\section{References}

[1] Aizawa, T.: Magnetic pressure seam welding method for aluminium sheets. Tokyo Metropolitan College of Technology. In: Journal of light metal welding and construction 200341 (3), PP. 20-25, Welding International, 2003.

[2] Aizawa, T.; Kashani, M.; Okagawa, K.: Application of magnetic pulse welding for aluminium alloys and SPCC steel sheet joints. In: Welding Journal, Vol. 86, PP. 119124, 2007. 
[3] Andersson, J.: Magnetic Pulse Welding. A Literature Study. Research Report. Swedish Institute for Metals Research. In: US-AB, Stockholm, 2001.

[4] Belyy, I. V.; Fertik, S. M.; Khimenko, L. T.: Electromagnetic Metal Forming Handbook. Vischa Shkola, Khar'kov State University, Polytechnics Institute, Khar'kov, USSR. A translation of the Russian book: Spravochink PO Magnitno-Impul Snoy Obrabotke Metallov by Altynova, M. M. At The Ohio State University, Materials Science and Engineering Department, 1996.

[5] Blakely, M.: Filler wire is for WIMPS (Welding). In: Fabricating and Metalworking, the business of metal manufacturing, Hirotec America, PP. 31-32, 2008. http://www.highbeam.com/doc/1G1178941793.html 13.09.2009.

[6] Daehn, G. S.: High velocity metal forming. In: ASM Handbook, volume 14B, metalworking: Sheet Forming, ASM International, PP. 405-418, 2006.

[7] Kamal, M.: A Uniform Pressure Electromagnetic Actuator for Forming Flat Sheets. The Ohio State University, Dissertation, 2005.

[8] Kaye, R. J.: Operational requirements and issues for coilgun EM launchers. Sandia national laboratories, IEEE 2004.

[9] Kleiner, M. ; Beerwald, C.; Homberg, W.: Analysis of process parameters and forming mechanisms within the electromagnetic forming process. In: CIRP Annals, Vol.54, issue 1, PP. 225-228, 2005.

[10] Kore, S. D.; Date, P. P.; Kulkarni, S. V.: Electromagnetic impact welding of aluminium to stainless steel sheets. In: Journal of
Materials Processing Technology. Vol. 208, page 486-493, 2008.

[11] Kore, S. D.; Date, P. P.; Kulkarni, S. V.: Electromagnetic impact welding of $A L$ to $A L$ Li sheets. In: Journal of manufacturing science and engineering. Vol. 131/034502(14), 2009.

[12] Masumoto, I.; Tamaki, K.; Kojima, M.: Electromagnetic welding of aluminium tube to aluminium or dissimilar metal cores. In: Transactions of the Japan welding Society. Vol.16, No. 2, PP. 110-116, 1985.

[13] Prasad, Nk.; Ram, Y.; Sabharwal, TP.; Pathak, K.; Kumar, M.; Matkar, AW.; Rajawat, RK: UHV compatible AL to SS joining through Electro Magnetic forming technique. In: International Symposium on Vacuum Science and Technology (IVS 2007), IOP Publishing Ltd, Journal of Physics: Conference Series 114/012046, 2008.

[14] Pope, B.: Hirotec bringing magnetic pulse welding to masses. In: Word's Auto Word, Vol. 11, No. 1, P7, 2007.

[15] Shribman, V.: Magnetic pulse welding of automotive HVAC parts, Pulsar Ltd, Aug. 2007.

http://www.pulsar.co.il/technology/?did=20. 15.09.2009.

[16] Shribman, V.; Blakely, M.: Benefit of the magnetic pulse process for welding dissimilar metals. In: Welding Journal, PP. 56-59, 2008.

[17] Uhlmann, E.; Jurgasch, D.:New impulses in the forming of magnesium sheet metals. In: The $1^{\text {st }}$ International Conference on High Speed Forming. Dortmund, Germany, 2004.

[18] Weman, K.: Welding Processes Handbook. Cambridge: Woodhead publishing Ltd, England, and CRC Press LLC, North America, USA, 2003. 
[19] Yu, H.; Li, C.; Zhao, Z.; Li, Z.: Effect of field shaper on magnetic pressure in Electromagnetic forming. In: Journal of Materials Processing Technology, Vol. 168, PP. 245-249, 2005.

[20] Zhang, P.: Joining Enabled by High Velocity Deformation. The Ohio State University, Dissertation, 2003.

[21] ELMAG INC.: Operation and maintenance manual for the ELMAG $60 \mathrm{KJ}$, Elmag, Inc., San Diego, CA, USA, 2003.
[22] ESAB: Magnetic pulse welding, ESAB AB Welding Automation, Sweden, 2001.

[23] Pulsar Ltd.: Magnetic Pulse Welding Solutions, Pulsar Ltd. Raanana, Israel, 2006. http://www.pulsar.co.il/systems/?did=30 5.9.2009.

[24] PST products $\mathrm{GmbH}$ : Electro-magnetic pulse technology of PST products. http://www.pstproducts.com/html/empt syste me.html.10.10.2009. 